\title{
Experts' Attitudes towards Web-based Instructional System for Algorithm
}

\author{
Kavita Saini \\ Assistant Professor \\ IEC College of Engineering \& \\ Technology \\ Greater Noida, India
}

\author{
Abdul Wahid \\ Head of Department of CS \& IT \\ MANUU, Central University, \\ Hyderabad, India
}

\author{
G N Purohit \\ Dean of Department of Apaji \\ Institute of Mathematics \& \\ Applied Computer Technology \\ Banasthali University \\ Banasthali, India
}

\begin{abstract}
The extreme progress of information and communication technologies (ICT) and use of Internet is attracting huge number of learners and educators. Latest technologies have been extensively taken up by web users and various factors are influencing such a high adoption rate. Equally use of Web-Based Instructional systems (WBIs) is becoming very popular and demanding among the instructors and the learners for the purpose of the distribution and delivery of the study material, and other education resources.
\end{abstract}

The paper is written with intention to examine factors influencing web-based learning. A tool AlgoWBIs developed for learning algorithm, which had been evaluated by the computer science instructors to find out whether the tool will help in effective learning or not? This study was conducted to explore, if the presented WBI tool is useful for learning or not.

The paper focuses on how to trim down the challenges of learning algorithm. In an attempt to facilitate teaching, learning and analysis of algorithm, a tool named AlgWBIs is developed and evaluated. The evaluation proves that the tool will improve the effectiveness of computer facilitated learning and will assist computer science graduate and undergraduate learners and educators.

\section{Keywords}

Algorithm, Instructional design, Web-Based Instruction system (WBIs), Meta learning, Self-paced learning, WebBased learning, Interactive learning, computer based learning, personalized learning

\section{INTRODUCTION}

Today, the utilization of web-based applications in professional studies is a popular method in education (Ferdig, 2005). Interactive learning, in contrast to the traditional learning is more influential for the learners and the instructors. Use of interactive learning tools are in favour of entire education system. As such, various fully and partially interactive learning tools are developed for distribution and delivery of education. These tools provide the solution for the problem of current learning system and create an innovative learning environment ( Tutkun, 2011). These tools perform either synchronous or asynchronous communication between the learners and eductors.
Keeping the benefits of Web-Based Interactive learning in mind a tool AlgoWBIs is developed. AlgoWBIs supports numerous features of interactive learning and supports the instructors and the learners of the information technology and computer science graduate and undergraduate courses.

AlgoWBIs is supporting algorithm learning, various examples, exercises and self assessment approach to test knowledge level (Garmpis, 2011) for the various sorting techniques.

The paper starts with the literature review, which discusses about the research done in interactive learning and summarize with various interactive tools. Then after paper describes about the inspiration behind the development of algorithm learning tool named AlgoWBIs. The development model used to develop AlgoWBIs is discussed further. After model used to develop the tool description of various builds is given. Then the most important experts' review is explained. Limitations and future work is also explained at the end of paper.

\section{LITERATURE REVIEW}

Abazi-Bexheti et al. (2007) reviewed and concluded with an Interactive Multimedia Learning Systems (IMLS). The main objective of the researchers is to create an additional learning tool that combines on-screen text, graphics, animations, audio and video. The researcher concluded with the tool in order to improve the learning process. Ružić-Dimitrijević, L. \& Dimitrijević, M. (2010) did a survey of IT instructors, who teach at various colleges and universities in several countries. They discussed the challenges met by IT (Information Technology) instructors. One of the challenges IT instructors face, is the fast speed of the IT development and thus having frequently updated course syllabuses, and this is especially true for introductory IT courses. They designed an introductory IT course for the instructors and the learners. The basic goal of an introductory IT course is to produce technically literate students who can use a computer at workplace or at school. The content of an introductory IT course has to expand to satisfy the extended definition of technology literacy. The goal of their research was to collect ideas and recommendations for the instructors of specific IT areas to help for improving their process of self-education, and help to overcome other challenges they may face.

Zhihai et al. (2011) have analyzed and designed one system according to the developing theory of software engineering, 
and built a functional module. The module is established and implemented for $\mathrm{C}$ programming course as an example of online learning system. The module is implemented by using MySQL and Dreamweaver software. Takano et al. (2011) have introduced a prototype system for learning tennis. Researchers have designed a Web-Based Multimedia Sport Instructional System to give training of tennis with the objective to save time, space, and cost of training as compared to the traditional human coaching approach.

Lee, YC. \& Terashima, N. (2012) has constructed A Distance Instructional System Moodle-Based Educational System which provides friendly interface to fit most students in elearning. Where Moodle is the Modular Object Oriented Developmental Learning Environment. The modified Moodlebased educational system allows help in obtaining the browsing time of each web page for students. Further by analyzing the recorded information, instructors can find out factors which will affect students' learning performance, so as to apply the proposed learning performance evaluation mechanism to evaluate students' learning performance for providing adequate auxiliary learning materials to individual students.

Hsu, CM. (2012) studied and summarized the web-based learning platform of Computer Support for Collaborative Design (CSCD). The platform is based on theories related to a constructive learning environment model, computer-supported collaborative learning and mind mapping. The platform provides effective tools for interaction and collaborative learning by integrating the tools of mind mapping into a learning environment that utilizes CSCD and conforms to the needs of design students.

Their research includes the design and set up of a teaching website with the constructivist learning environment model, computer-supported collaborative learning theory, and mind mapping-related theories that serve as the basis, to design and set up a teaching website that aids in understanding the influence of the CSCD and collaborative mind mapping on design department students' learning attitudes, learning effectiveness, and creativity.

Kim, D.G, Lee, J. (2013) proposed the development of a webbased, intelligent instruction system to help elementary school students for mathematical computation after reviewing various researches in the same area. Researchers concentrated on the intelligence facilities which support diagnosis and advice. According to the researchers existing web-based instruction systems merely give information on whether the learners' answers are 'correct' or 'incorrect', and only offer evaluation of the learners' results in terms of points. Researchers proposed a system which diagnoses the learner's comprehension status, and provides explanations: why did the learner make the error? The proposed system has a facility that analyses the learner's weak points and has the ability to diagnose the cause of the error, giving advice to the learners and more detailed error information than extant systems.

\section{INSPIRATION FOR THE AlgoWBIS DEVELOPMENT}

Literature proves that there are numerous benefits of interactive learning over traditional learning for graduate and undergraduate computer science learners. The traditional learning has many defeciencies for complete and disciplined learning of algorithms. Geographical barriers among the learners and instructors, cultural barrier, one-to-one assistance are the major problems of face-to-face-traditional learning. Unlike Web-based learning time limitations for both learner and instructor is also major limitation of face-to-facetraditional learning.

In India Web-Based Instructional system are not widely used as teaching aid. So it is necessary to focus on such tools for learning. WBIs can be valuable in making learning interesting and effective. The benefits include the encouragement and engagement of learners to think, write and to talk about the topic during learning. Interactive learning helps the learner to be more dynamic and active. It has the potential to transform the way of teaching and learning across the board.

Varieties of Web-Based Instructional systems are available for effective learning. Literature supports that tool for computer programming, operating system, multimedia, driving learning are offered by various researchers. But there is not a satisfactory interactive tool for algorithm learning, so there is a need to develop a framework for teaching algorithm using WBIs.

AlgoWBIs tool is developed with intensions to reduce the deficiencies of traditional learning of algorithm. The tool is developed to overcome the constraints imposed upon traditional teaching of algorithms for professional studies. The constraint that is identified in traditional learning is the lack of ability to practice in-depth step. The lack interactivity and timely feedback from the learners is also a barrier in traditional learning that is being removed with the presented tool. One of the major constraints with traditional learning is that the instructors could not provide assistance to the individual learners while implementing algorithm, while AlgoWBIs would provide assistance individual learners.

AlgoWBIs tool presents algorithm learning, interactive examples and exercises. Tool also facilitates self assessment of learners. The tool presented here encourages the learners of algorithms to be more active and attentive during learning.

\subsection{AlgoWBIs model a Perspective Model}

The selection of the model is the key approach to improve the interactivity of learning tool. After judging, suitability of Anita Lee-Post's perspective model and incremental model, the model shown in Figure-1 is adopted to develop the tool. The model is addressing the questions like how to design, develop, verify and validate the tool. 


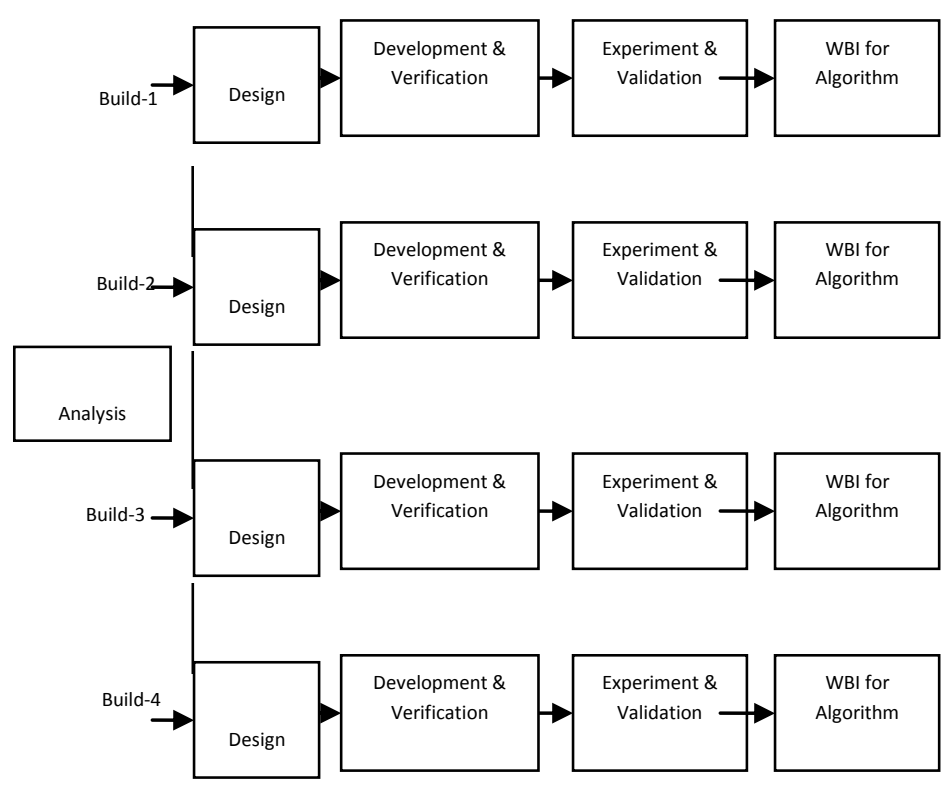

Figure-1: Perspective Incremental Life cycle model for WBI for Algorithm

The model has an analysis phase that allows defining various features and functions to be part of the tool for the purpose to improve the interactivity and usability of the same. The design, development, experiment and validation has been done for each built separately, where each build is a separate algorithm. Each built sums up with the running software.

\subsection{AlgoWBIs Builds: Description}

The major challenge in facilitating educators is providing them a meaningful and interactive learning tool (Thomas, R). It requires diversified knowledge including knowledge of interactive tools along with the programming skills, and command on the subject for which tool is being developed. Knowing the learner's ability and grasping of contents is extremely helpful for the success of such tools (Kennedy, 1998).

Tools interactivity helps in engaging learners during learning that is why the focus should be on how to increase the interactivity? The main features of interactive tool include interactivity, self assessment, navigation between topics, relevance and coverage of content.

Content of this tool will be relevant to fulfill the needs of the computer science graduate and undergraduate courses. The tool AlgoWBIs covers all the relevant content for algorithm learning. It is also considered the depth of the topic is sufficient. "Learning might suffer if the sequence is chosen improperly" (Abazi-Bexheti et al.), For the purpose of improvement in learning it is required to develop a learning tool having the proper sequence of topic coverage, which has been taken care of.

Another focus is given on content's navigation. Learners should be equipped with the freedom to navigate to the topics to some extend (Abazi-Bexheti et al.). To assess learner's knowledge appropriate quizzes is required with online evaluation. In order to enhance learning Evaluation is done by the tool immediately after learner go through the self assessment. This evaluation supports learners to judge their knowledge level after learning any topic.

Extendibility of the tool is also possible when required. This feature will reduce the cost of learning and development of new algorithm learning tools. The tool addresses the personalized needs of the learners which would nurture their knowledge and skills. Further the system would bridge the gap between the learners and the instructors during learning algorithms and would promote the platform for sharing their ideas and knowledge.

This paper has comprehensive descriptions related to the development of the presented tool. The tool presents the learner with a sequence of choices, each containing subchoices or sub-menu. The learner can respond by choosing one of the choices given and system performs a corresponding action. Learning options provided with the tool are selection sort, bubble sort, insertion sort and quick sort.

The development of the tool starts with the splash screen. After the splash screen learner's interface would present learning options as mentioned above. Depending on the current knowledge level individual learner may start learning. Unlike classroom learning each learner independently can start learning rather than forcing them to go with the topic being taught in the classroom.

The tool is developed in such a manner that the learners first will go through the details of the topic and would include the basic concepts also. After learning the topic example would be presented for better understanding. After the start of the interactive example, if a learner wants to go through the topic again $\mathrm{s} / \mathrm{he}$ can navigate. An exercise will be given after going through the example. If the learner is competent enough to complete the given exercise must go through the topic again.

Finally the self assessment quiz is presented which helps the learner to assess their knowledge level. Once the learner clears the one level can move to the further topic. It is clearly defined what action is required to take further. A learner could navigate through a topic is being learned and could navigate to the main menu. Other than four learning options, menu also has an exit option to quit from the main menu. Each sorting has four sections:

Tool has various sections for solving various purposes. One of them is about the topic to be learned in each module. This section covers all the aspects of particular sorting. It includes an introduction, algorithm for sorting, sorting function written in $\mathrm{C}$ programming language and complexity of sorting. The learner can navigate backward and forward within the given options using navigation buttons. If the learner wants s/he can exit from the topic any time and come to the main menu.

The next section example allowed learners to investigate the properties of various algorithms and to enhance the knowledge of learner by showing simulation. It allows the students to understand how sorting algorithm works.

The exercise section is consisting of a problem provided to learners. To do the exercise learners are required to use knowledge extracted from the prior sections. It is a highly interactive section, allowing learners to make use of knowledge to explore and judge their understanding of the topic. Here learners are asked to move array values to the correct positions interactively. Exercise is the most important option for the learners associated with each sorting.

The last section quiz allows learners to measure their knowledge by providing various quizzes. This self assessment section allows learners to test knowledge they gather from the previous sections. Each quiz has fifteen questions with multiple choices of answers, among which only one answer 
will be correct. The learner will be asked to select a single correct answer for each question. Answers of the questions will be evaluated automatically by system and finally result will be displayed to the learner. The result of the quiz will be helpful to let the learner know about the knowledge level (Millard et al., 1997).

Other than the above mentioned options, an exit option in each topic allows learners to quit from the topic being learned. There is a menu button to allow learners to go on the main menu of the tool. Going through all above mentioned options is very simple as tool is very interactive and user friendly.

The overall functionality of tool is depicted in figure-3. Initially when learner interacts with the system will go through the login verification. After successful verification learning options will appear, which includes insertion sort, quick sort, bubble and selection sort. The figure also has a proposed algorithm to be implemented in future.

All these sorting algorithms have multilayer process in which first layer covers the details about sorting, second layer covers the example for each algorithm where as third layer, simulation is the most interactive in nature and asks the learners to move array values to the desired positions according to the sorting technique and fourth and last layer allow learners to check their progress in terms of quizzes for each algorithm learned before.

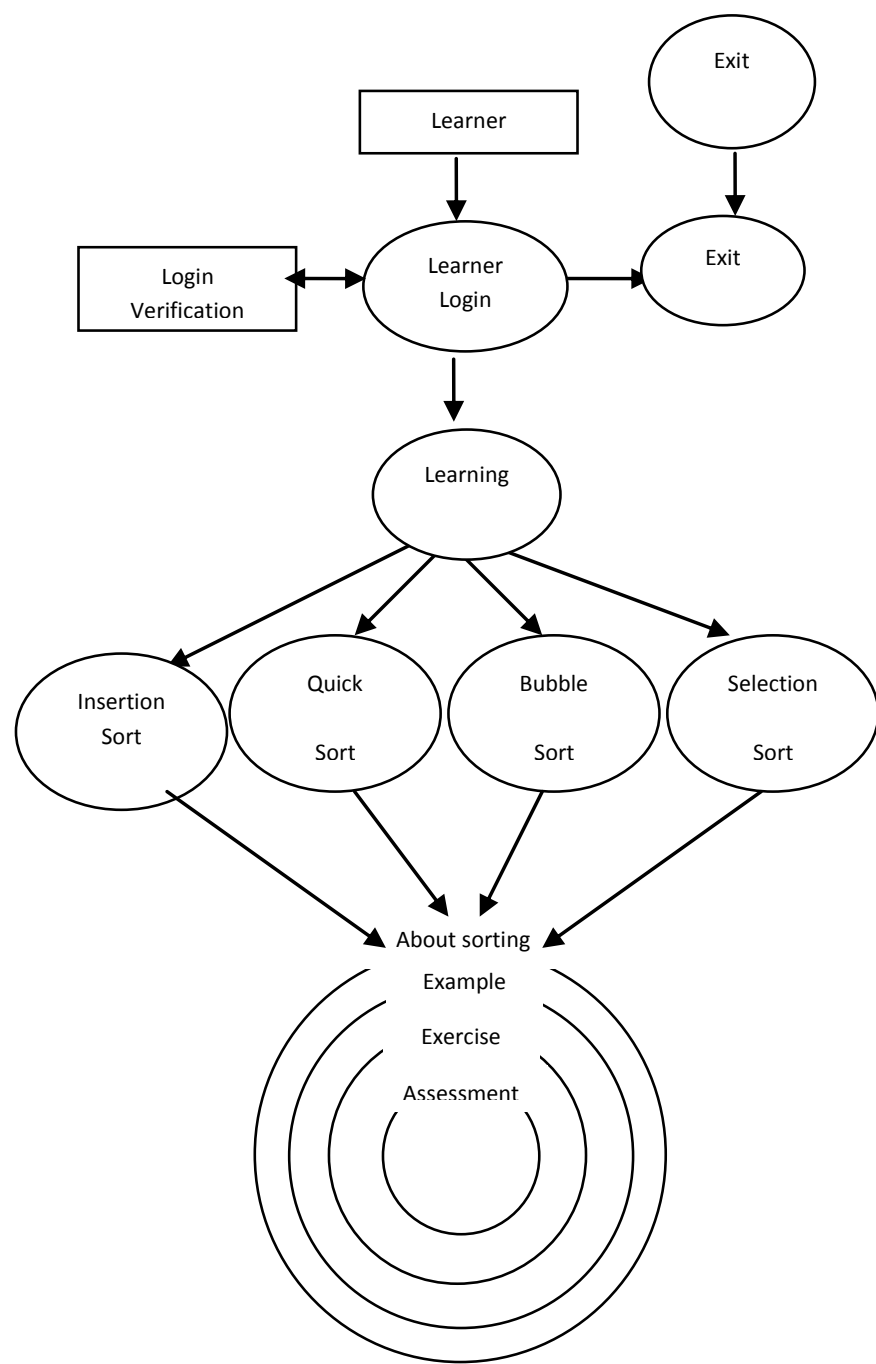

Figure-3: Functionality of tool AlgoWBIs

\subsection{Experts' Review}

Experts' review will plays vital role in order to improve the tool if required. After development of the various builds of tool, it has been evaluated by fifty experts. Various evaluation parameters have been covered to check the effectiveness.

Review is done by the experts, who are involved in teaching various courses including MCA, M.Tech. (Computer Science and Information Technology) and other graduate and under graduate programs of Computer Science and Information Technology. The reason for choosing these experts is that these are efficient enough to understand the usefulness and effectiveness and the short comings of AlgoWBIs tool for algorithm learning better than anybody else. They could compare the learning of the algorithm using AlgoWBIs tool with the traditional learning as well as with any learning tool available online.

The survey is done with face-to-face interaction with experts. First they were requested to work with the tool outside the class room, to check whether the tool would be useful for the learners or not.

Then experts were requested to fill up questionnaire covering twenty two questions as listed in Table-1. The questions were covered to check whether the tool is effective in learning even without face-to-face interaction among the instructor and the learners, content provided with the tool, explanation and organization of the content and many more. The relevance and adequacy of the content is also checked by the experts. Experts have also examined whether the AlgoWBIs tool could be used as an independent learning tool or could be used along with the traditional teaching pedagogy for the benefit of learners. The tool has been compared with the Computer Based Trainings.

Likert scaling technique has been used as data collection instrument. The descriptions of the scales have been described below:

Strongly Disagree Neutral Agree Strongly

Disagree Agree

$\begin{array}{llllll}1 & 2 & 3 & 4 & 5\end{array}$

The evaluation parameters and responses in percentage are listed in the following Table-1:

\begin{tabular}{|l|c|c|c|c|c|}
\hline \multicolumn{1}{|c|}{ Evaluation Parameters/Response } & $\mathbf{1}$ & $\mathbf{2}$ & $\mathbf{3}$ & $\mathbf{4}$ & $\mathbf{5}$ \\
\hline Overall Functionality & $0 \%$ & $6 \%$ & $12 \%$ & $38 \%$ & $44 \%$ \\
\hline Easy to use & $0 \%$ & $0 \%$ & $16 \%$ & $32 \%$ & $52 \%$ \\
\hline Effectiveness on learning & $0 \%$ & $2 \%$ & $22 \%$ & $44 \%$ & $32 \%$ \\
\hline Understanding of contant's Language & $0 \%$ & $4 \%$ & $4 \%$ & $30 \%$ & $62 \%$ \\
\hline Concept understanding & $0 \%$ & $2 \%$ & $12 \%$ & $48 \%$ & $38 \%$ \\
\hline Depth and Relavance of Contant & $0 \%$ & $10 \%$ & $30 \%$ & $36 \%$ & $24 \%$ \\
\hline Adequacy of content & $2 \%$ & $4 \%$ & $18 \%$ & $50 \%$ & $26 \%$ \\
\hline Organization of information & $2 \%$ & $8 \%$ & $0 \%$ & $54 \%$ & $36 \%$ \\
\hline Navigation through Topics & $2 \%$ & $2 \%$ & $12 \%$ & $46 \%$ & $38 \%$ \\
\hline
\end{tabular}




\begin{tabular}{|l|c|c|c|c|c|}
\hline Clarity of On-Screen Messages & $0 \%$ & $2 \%$ & $12 \%$ & $54 \%$ & $32 \%$ \\
\hline Interactivety of Tool & $4 \%$ & $2 \%$ & $12 \%$ & $36 \%$ & $46 \%$ \\
\hline $\begin{array}{l}\text { Encouragement of Self-Disciplined } \\
\text { Learning }\end{array}$ & $0 \%$ & $8 \%$ & $14 \%$ & $32 \%$ & $46 \%$ \\
\hline Accomplishment of Objective & $6 \%$ & $0 \%$ & $12 \%$ & $46 \%$ & $36 \%$ \\
\hline Assessment of Learner's Knowledge & $0 \%$ & $6 \%$ & $14 \%$ & $40 \%$ & $40 \%$ \\
\hline Association with Traditional Learning & $2 \%$ & $4 \%$ & $16 \%$ & $34 \%$ & $44 \%$ \\
\hline Independent from Traditional Learning & $6 \%$ & $8 \%$ & $14 \%$ & $42 \%$ & $30 \%$ \\
\hline Better Than CBT & $4 \%$ & $4 \%$ & $22 \%$ & $38 \%$ & $32 \%$ \\
\hline Error Free & $2 \%$ & $4 \%$ & $10 \%$ & $26 \%$ & $58 \%$ \\
\hline Effective for Algorithm Learning & $2 \%$ & $4 \%$ & $12 \%$ & $44 \%$ & $38 \%$ \\
\hline Easy to Find Information & $0 \%$ & $6 \%$ & $14 \%$ & $46 \%$ & $34 \%$ \\
\hline Look and Feel of Interface & $0 \%$ & $4 \%$ & $14 \%$ & $36 \%$ & $46 \%$ \\
\hline $\begin{array}{l}\text { Effectiveness of WBI for learning } \\
\text { algorithm }\end{array}$ & $2 \%$ & $6 \%$ & $0 \%$ & $48 \%$ & $44 \%$ \\
\hline
\end{tabular}

Experts' response shows that the tool is overall beneficial for the learners and instructors. There were, of course, also negative comments. To help improve the delivery of algorithm learning for various programs. One of the negative comments was regarding the color combinations used in the tool, while other was related to include more algorithms.

These negative comments were important in order to improve the interactivity and over all learning through the tool. These are comments are dissatisfaction of color combination used, number of algorithm covered could be more, time used during examples should be increased.

Considering the comments tool will be changed and will be implemented for learners in various colleges. Where AlgoWBIs will be validated by the learners themselves. To evaluate the effectiveness of the tool, validity of the tool leading to Assessment of critical inferences, four learner groups will be selected, which will be labelled G-1, G-2, G-3, and G-4. These groups will comprise of B. Tech. and MCA. The groups will be selected randomly and there will be 20 to 25 learners in each group and result will be evaluated.

\subsection{Where to implement AlgoWBIs?}

AlgoWBIs can be implemented in various colleges and universities offering BCA, MCA, B.Tech Computer Science, and other computer science programs where Algorithm or data structure is part of the curriculum. Till date the tool is not covering all the algorithms so could not be used as an independent tool rather could be use as a teaching aid to facilitate instructors and learners.

\subsection{Limitations}

The AlgoWBIs is developed to support interactive learning and to improve the efficiency of the learners and the instructors.

Computer literacy has been improved a lot but still there may not be full utilization of the tool by the learners and the instructors without proper training, however messages are being prompted whenever required.

Further the number of algorithm implementation in the tool is another limitation. In spite of covering all algorithms, the tool facilitates the learning for sorting algorithms. At present insertion sort, quick sort, bubble and selection sorting has been included.

\subsection{Conclusion}

The evaluation and study summarized with a highly interactive tool to reduce the efforts of learning. Evaluation shows that the tool is able to make the learning easy and interactive.

The emphasis of the paper is on the evaluation of tool on various parameters. These parameters leave impact on the learning. further version will be developed and implemented to cover learning of searching algorithms.

Although this tool fulfils most of the learning requirements for sorting, there is always scope for upgradition. The tool will be expanded in future to cover more algorithms and

\section{REFERENCES}

[1] Sessoms, D., "Interactive instruction: Creating interactive learning environments through tomorrow's teachers." International Journal of Technology in Teaching and Learning, Vol. 4(2), PP 86-96, 2008.

[2] Garmpis, A. "Design and Development of a Web-based Interactive Software Tool for Teaching Operating Systems." Journal of Information Technology Education, Vol. 10, 2011.

[3] Malmi, L., Karavirta, V., Korhonen, A., Nikander, J., Seppälä, O., and Silvasti, P. "Visual Algorithm Simulation Exercise System with Automatic Assessment: TRAKLA2." Informatics in Education, Vol. 3(2), PP 267-288, 2004

[4] Arthur, J. D., "A Descriptive/Prescriptive Model for Menu-Based Interaction". International Journal of ManMachine Studies Vol. 25(1), PP 19-32, 1986.

[5] Lee-Post, A., "e-Learning Success Model: an Information Systems Perspective." Electronic Journal of e-Learning Vol. 7(1), pp 61 - 70, 2009 available online at www.ejel.org

[6] Ludewig, J., "Models in software engineering - an introduction, Softw Syst Model." 2: 5-14 , 2003/ Digital Object Identifier (DOI) 10.1007/s10270-003-0020-3

[7] Thomas, R., "Interactivity \& Simulationsin e-Learning". Avaiable at http://www.multiverse.co.uk/whitepaper.pdf

[8] Kennedy, D.M., "Software Development Teams In Higher Education: An Educator's View." Software Development Teams in Higher Education: An Educator's View, 1998

\section{[9] doi: 10.1109/ITI.2007.4283784}

[10] Millard,D., Jennings, W., Sanderson A., Wong,A. Patel, A. Brubaker, W., Perala, M. \& Slattery, D., "Interactive Learning Modules for Electrical, Computer and Systems Engineering." Frontiers in Education Conference, 1997. 27th Annual Conference. Teaching and Learning in an 
Era of Change. Proceedings., vol.3, no., pp.1165,1170 vol.3, 5-8, 1997 doi: 10.1109/FIE.1997.632624

[11] Nikolaou, A., Koutsouba, M., "Incorporating 4MAT Model in Distance Instructional Material- An Innovative Design." European Journal of Open, Distance and ELearning, 2012. Retrieved from http://www.eurodl.org/?article $=497$

[12] Bellotti, F., Berta, R., De Gloria, A., \& Primavera, L., "Supporting authors in the development of task-based learning in serious virtual worlds." British Journal of Educational Technology, Vol. 41(1), PP 86-107, 2010.

[13] Hadjerrouit, S., “A Conceptual Framework for Using and Evaluating Web-Based Learning Resources in School Education." Journal of Information Technology Education, Vol. 9, PP 53-79, 2010.

[14] Kelly, P., \& Stevens, C., "Narrowing the distance: using e-learner support to enhance the student experience." European Journal of Open, Distance and E-Learning, Vol. 2, 2009.Retrieved from http://www.eurodl.org/materials/contrib/2009/Kelly_Stev ens.pdf

[15] Hansen, S.R. \& Narayanan, N. H., "On the role of animated analogies in algorithm visualizations." In: Proceedings of the Fourth International Conference of The Learning Sciences, Lawrence Erlbaum Associates, Mahwah, NJ, PP. 205-211, 2000.

[16] Seay, F. \& Catrambone, R., "Using animations to help students learn computer algorithms: A task analysis approach." In: Artificial Intelligence in Education (J. D. Moore et al. eds.), IOS Press, PP 43-54, 2001.

[17] Craig Larman, Victor R. Basili., "Iterative and Incremental Development: A Brief History." IEEE Computer (IEEE Computer Society) Vol. 36 (6), PP 4756, 2003. doi:10.1109/MC.2003.1204375. ISSN 00189162. Retrieved 2009-01-10, 2003.
[18] Lee-Post, A., “e-Learning Success Model: an Information Systems Perspective." Electronic Journal of e-Learning, Vol. 7(1), PP. 61 - 70, 2009 Available: www.ejel.org

[19] Antonovičs, U., Priednieks, E.., "Interactive Learning Tools for Electrical Engineering and Electronics Course." Electronics And Electrical Engineering, 2006

[20] Jose' Luis Guzma'n , Karl J. A stro“m , Sebastia'n Dormido ,Tore Hagglund, Yves Piguet., "Interactive learning modules for PID control." Control Systems, IEEE, Vol. 28(5), PP 118-134, 2008.

[21] Dormido, S., Pisoni, E. \& Visioli, A., "Interactive tools for designing fractional-order PID controllers." International Journal of InnovativeComputing, Information and Control, Vol. 8(7), 2012.

[22] CHEN, Y.C., LIN, Y.C., YEH, R.C. \& LOU, S.J., "Examining factors affecting college students' intention to use web-based instruction systems: towards an integrated model." Tojet: the turkish online journal of Educational Technology, vol.12 (2), PP. 111-121, 2013

[23] Tutkun. O.F., "Internet access, use and sharing levels among students during the teaching-learning process" The Turkish Online Journal of Educational Technology, Vol. 10 (3), PP. 152-160, 2011

[24] Ferdig, R.E., "Towards implementing technologies in education: Exploring the pedagogy and people of good innovations." The Turkish Online Journal of Educational Technology, Vol. 4 (2), PP. 35-43, 2005.

[25] Tutkun. O.F., "Internet access, use and sharing levels among students during the teaching-learning process." The Turkish Online Journal of Educational Technology, Vol. 10 (3), PP. 152-160, 2011.

[26] Saini, K., Wahid, A., \& Purohit, G.N., "Design and Development of AlgoWBIs." International Journal of Advanced 